\title{
TBI.02. Traumatic brain injury prevention campaign in Sobral: an experience report
}

\author{
SILVA, R.R ${ }^{1 *}$, ARY, C.C ${ }^{1}$, TEIXEIRA, S.C ${ }^{1}$, FILHO, G.C² \\ 1 - Universidade Federal do Ceará \\ 2 - Departamento de neurologia da Santa Casa de Misericórdia de Sobral \\ *Email: renataramosmed@gmail.com
}

Introduction: Traumatic brain injury (TBI) is the leading cause of morbidity and mortality worldwide in individuals younger than 45 years old, and most commonly affects the age group between 15 and 24 years. It can be a result of traffic accidents (auto, cycling, cycling bike, pedestrian), falls, assaults, firearm injuries, disasters, sports and other less common causes. TBI is present in $40 \%$ of trauma victims, $20 \%$ of these individuals end up dying on the spot or within 24 hours of admission and $80 \%$ in the first week after the accident. Objectives: This paper aims to describe the experiences of members of the Scientific Society of Neuroscience of Sobral during the educational campaign about traumatic brain injury. Methodology: In July 13th, 2013, a campaign for the prevention of TBI entitled "Think: Use your head to protect your body" was held in a public place, the Square of Cuba in Sobral, through where a large number of people pass daily. The population was targeted and addressed on the key factors triggering a severe traumatic brain injury and also what are the main ways to prevent such trauma. For this educational purpose, we used instruments such as posters, flyers and banners. Furthermore, attendants' blood pressure was measured in order to attract the interest of people to the local campaign. Results: During the campaign it was noted that the level of knowledge of the population about how to prevent traumatic brain injury is relatively low. Many had no notion of how to use the motorcycle helmet properly. Moreover, people who participated in the campaign often reported not wearing a helmet or seat belt when riding some motorized vehicle. During the campaign, as the population received information about traumatic brain injury, we noticed that it was possible to provide the population of Sobral a better understanding of the risk factors and the best ways to prevent TBI. We also provided to the passersby the instructions how to correctly use safety equipment, such as helmets and seat belts. Conclusions: This educational campaign as part of an extension project had a role to improve the knowledge of the population about traumatic brain injury. Thereby, helping to reduce the rates of $\mathrm{TBI}$ in Sobral.

SILVA, R.R.; ARY, C.C.; TEIXEIRA, S.C.; FILHO, G.C. 2013. Traumatic brain injury prevention campaign in Sobral: an experience report, p.28. In: Oriá, Reinaldo Barreto; Andrade, Geanne Matos de; Bruin, Veralice Meireles S. de. I International Symposium in Neuroscience Meeting [Blucher Neuroscience Proceedings n.1 v.1]. São Paulo: Blucher, 2014 http://dx.doi.org/10.5151/isnm-sine23

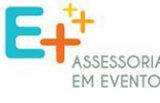

